SAND- $-90-1962$

DE9 1000459

\title{
STANDARDS LABORATORY ENVIRONMENTS
}

\author{
David W. Braudaway \\ Division 7342 \\ Sandia National Laboratories \\ Albuquerque, New Mexico
}

\begin{abstract}
Standards Laboratory enviroments need to be carefuliy selected to meet the specific mission of each laboratory. The mission of the laboratory depends on the specific work supported, the measurement disciplines required and the level of uncertainty required in the measurements. This document reproduces the contents of the Sandia National Laboratories Primary Standards Laboratory Memorandum Number 3B (PSLM-3B) which was issued on May 16, 1988, under the auspices of the Department of Energy, Albuquerque Operations Office, to guide the laboratories of the Nuclear Weapons Complex in selecting suitable environments. Because of both general interest and specific interest in Standards Laboratory environments, this document is being issued in a more available form.
\end{abstract}

A. PURPOSE

The purpose of this dorument is to provide guidance in selection of laboratory environments suitable for standards maintenance and calibration operations. It is not intended to mandate a specific environment for a specific calibration but to direct selection of the environment and to offer suggestions on how to extend precision in an existing and/or achievable (practical) environment. Although this documents pertains specifically to standards laboratories, it can be applied to any laboratory requiring environmental control.

\section{B. BACKGROUND}

Environmental conditions in Standards Laboratories must be controlled within acceptable limits. These limits are dependent on the type of calibration done in the laboratory and the required uncertainty. Application of new equipment and techniques necessitate a review and possibly a revision of requirements. The specific mission in any measurements discipline may dictate a tighter or less stringent requirement.

At the Primary Standards Laboratory (PSL), studies have been under way on ways to optimize environments to measurement needs. This document the results of these studies and covers both those areas where environmental requirements can be relaxed and those where they must be tightened. Some 
proven techniques for circumventing environmental limitations are described; the need for assessing the effects of a recent out-of-control condition is emphasized. Where practical, requirements are parallel with those of ISA RP52.1, "Recommended Environments for Standards Laboratories," 1975. For additional helpful information, see ISO/R 554, "Standard Atmospheres," and NCSL RP\#7, "Laboratory Design."

Note: Caution is advised in referencing published standards. All standards and recommended practices have a mandatory 5-year review and update or reaffirm cycle. Many are well beyond this time period and have not been subject to the required review. Direct reference to these standards may find that they have been changed or or are no longer active.

\section{TEMPERATURE}

1. SELECTION OF NOMINAL TEMPERATURE. Only two nominal temperature values are used for environmental control of standards laboratories. These values are $20^{\circ} \mathrm{C}$ and $23^{\circ} \mathrm{C}$. Choice is dictated primarily by prevailing practice in the particular standards discipline, as follows:
a. $20^{\circ} \mathrm{C}$ : Dimensional and Mass,
b. $23^{\circ} \mathrm{C}$ : Force, Electrical (dc, ac low and high frequency), and most Physical Disciplines.

When operation at a temperature other than $20^{\circ} \mathrm{C}$ or $23^{\circ} \mathrm{C}$ is necessary, an evaluation of the effects of the non-standard reference temperature is required. The evaluation shall include an analysis of the corrections to values and/or the increase in uncertainty of measurements due to the non-standard temperature. Rational for the choice of temperature shall be included.

NOTE: For those measurement disciplines where use of dimensional standards is frequent, $20^{\circ} \mathrm{C}$ may be the preferable choice. However, electronic equipment operated in an ambient different from the $23^{\circ} \mathrm{C}$ calibration temperature usually has an offset (bias) for which correction may not be known and may be difficult to determine. Artifacts such as gage blocks and resistors which have well established temperature coefficients permit correction of value to a temperature other than the reference temperature, providing their actual temperature can be established.

2. LIMITS ON TEMPERATURE VARIATION. The allowed temperature variation changes with uncertainty level and discipline. Six temperature variation limits are specified in the table below and are keyed to their general application. For each laboratory mission, the level must be selected to match the requirements. Some methods of circumventing 
the undesired thermal effects are given in the notes to the table; see also 3 ., below.

NOTE ON VERY TIGHT TEMPERATURE CONTROL: Very tight temperature variation 1 imits, $1 . e . \pm 0.001^{\circ} \mathrm{C}$ to $\pm 0.01^{\circ} \mathrm{C}$, as required for standard cells (typical reference temperature $28^{\circ} \mathrm{C}$ or $30^{\circ} \mathrm{C}$ ) and precision resistors (reference temperature $25^{\circ} \mathrm{C}$ ), are normally achieved by use of an ofl-bath or an alr-bath. These baths require a laboratory temperature control of only moderate degree against which to achieve their internal temperature values. The laboratory variation is reduced by a factor of 200 to 10,000 in such baths; however, this reduction factor is not normally specified. It is usually necessary to monitor the apparent temperature inside the bath to assure the required degree of control and to make corrections to value. In application, resistors dissipate power but the energy is carried away by the fluid of the bath to preclude a significant temperature rise.

\section{TABLE: LABORATORY TEMPERATURE VARIATION LIMITS}

Variation Typical Application

Limit

$\pm 0.01^{\circ} \mathrm{C} \quad$ Highest precision dimensional measurement, direct measurement by physical or interferometric methods:

The limit of measurability in parts-per-million (ppm) may be computed by multiplying the temperature variation by the expansion coefficient (in $\mathrm{ppm}$ per ${ }^{\circ} \mathrm{C}$ ) and combining this with the resolution limit of the measuring apparatus.

$\pm 0.1^{\circ} \mathrm{C} \quad$ Precision dimensional and mass calibration.

In dimensional measurements, direct and comparison measurements to $1.5 \mathrm{ppm}$ of length for steel or $5 \mathrm{ppm}$ of length for aluminum.

Mass comparison of similar density weights with repeatability (buoyancy corrected) of $0.1 \mathrm{ppm}$ or better at $1 \mathrm{~kg}$ (actual useable values depend on balance resolution and measurement technique).

$\pm 0.25^{\circ} \mathrm{C} \quad$ High-quality mass calibration, precision force measurement, and high-precision dc calibration.

Repeatability (buoyancy corrected) of $0.25 \mathrm{ppm}$ or better at $1 \mathrm{~kg}$ for weights with similar densities.

Force measurement with a resolution limit of $50 \mathrm{ppm}$. 
Page 4

$\pm 0.5^{\circ} \mathrm{C} \quad$ Optics and general dimensional calibration.

Direct and comparison measurements to $5 \mathrm{ppm}$ of length for steel or $15 \mathrm{ppm}$ of length for aluminum.

$\pm 1^{\circ} \mathrm{C}$ ac, microwave, and most physical disciplines at the highest callbration levels, general dc calibration.

dc calibration at $10 \mathrm{ppm}$ and less precise levels; with measurement of temperature or use of controlled baths more precise work may be done.

$\pm 2^{\circ} \mathrm{C} \quad$ Radiation, general calibration in ac, microwave, and most physical disciplines.

Precise figures on ac calibration levels are not available; general practice is stipulated.

NOTES ON TEMPERATURE VARIATION LIMITS:

1. Measurement of the actual temperature of the artifact being calibrated almost always yields a lower uncertainty. The temperature of the artifact is more constant then that of the laboratory environment because of the averaging (integrating) effect of equipment and/or artifact thermal time constants.

2. Temperature may meet the selected variation constraint but not be at nominal value because of uncontrollable room gradients. Gradients may arise from non-uniform airflow, heat dissipated by the artifact, heat dissipated by the measuring equipment, and heat from personnel. Measurement of actual artifact temperature is necessary for meaningful corrections to be applied.

3. Heat sources, including lights and personnel, are especially troublesome in the tighter environments. An adaptive control system can be advantageous in compensating for the heat output of one or more persons (approximately 100 watts per person).

4. Extended, non-measurement, warm-up times are required for most high-precision balances to achieve stable operation. The principal contributor is heat from the operator. Reduction of non-productive operator time can be achieved by use of a heat source to warm-up the equipment. For more information on the technique see David $h$. Braudaway, "Minimization of Operator-Balance Interactive Warm-Up by Use of an 'Alter Ego' Heat Source," IEEE Transactions on Instrumentation and Measurement, Vol. IM35, No. 4, Part 1, Dec. 1986, pp 404-408.

5. Floor-to-ceiling vertical laminar air flow is recommended to 
minimize gradients in $\pm 0.01^{\circ} \mathrm{C}$ and $\pm 0.1^{\circ} \mathrm{C}$ controlled environments. Small room(s) are necessary to accomplish the result. For other control limits, normal air conditioning practice is adequate.

6. For dimensional equipment, the time to achleve acceptable equilibrium with the environment is long because of machine and artifact thermal time constants. During the equilibration period, measurements are not practical even though the air temperature meets its required limit, unless temperature of test and reference artifacts are measured and corrections applied.

7. Averaging of temperature from several points in a laboratory may be necessary to produce a more representative control value. Electrical or physical sampling may be accomplished but the latter is easier to troubleshoot and is preferred.

3. TEMPERATURE RECORDS. To know that the temperature is within acceptable bounds at any time and that it has remained sufficiently so for an acceptable time period, it is required that a continuous recording of the air temperature be maintained for each controlled laboratory area. This produces a permanent record of the air temperature. However, many artifacts (e.g., resistors) and most measuring equipment (electrical/ electronic or physical/dimensional) dissipate power. These devices are above air temperature in use, from $0.1^{\circ} \mathrm{C}$ to about $10^{\circ} \mathrm{C}$ (shunts run much higher than this at rated current). Precise metrology often requires measurement of the actual temperatures for correction of value(s) and for assurance that the temperature is sufficiently constant during measurement. Such actual temperature values are not readily amenable to recording; however, the temperature used in applying corrections must be measured using a calibrated instrument. The following general measurement rules apply:

a. Measurement in the physical disciplines and most of the electrical disciplines is acceptable if the laboratory temperature is in control and has remained so for the past four hours. This four hour period is also the duration of warm-up often used to stabilize electronic instruments but some instruments may require an overnight warm-up. An exception exists with high-precision resistors used in air where the internally dissipated power mandates measurement of temperature and application of temperature coefficient correction or operation at significantly degraded uncertainty levels.

b. Mass has some special requirements which are dependent on balance design. Two-pan balances do not show large effects from operator heat input. Electronic balances require the normal warm-up expected for electronic equipment and, in addition, may show an effect from thermal input of the operator. Single-pan balances require specific warm-up operation to minimize the thermal input 
from the operator before meaningful weighing may be accomplished. This warm-up is balance dependent and may be 45 minutes or more. As listed in note 6 . above, an "alter ego" heat source may reduce wara-up to a more practical time. In all cases, the weights must have been allowed to come to an equilibrium with the environment inside the balance chamber to preclude circulating air currents and the resulting bias forces. Weight-balance equilibration time is dependent on the mass of the weights and the characteristics of the balance.

c. Dimensional measurements are significantly affected by both the past and the present temperature of the laboratory. In general, laboratory temperature being within variation limits is a sufficient condition only for some relatively-low precision measurements.

For precise measurements, the measuring equipment and both reference and subject artifacts must be allowed to come to substantial equilibrium with the laboratory environment. Because of large thermal mass and low conductive coupling to air, measuring equipment shows a substantial time constant for recovery from a thermal offset. The time constant is equipment-dependent, with a range from a few hours to more than a week for large coordinate measuring machines. Several time constants under controlled conditions may be required in advance of the measurement depending on the magnitude of the thermal offset to which machine and/or artifacts may have been subjected. The problem is exacerbated when a low-conductivity material, such as granite, is involved. For such materials, significant temperature gradients and dimensional offsets within the structure are expected for an extended period of time. Evaluation of the recent history of laboratory control and the behavior of artifacts under test is required for all

measurements. Measurement of the temperature of the artifact under test is often helpful and may be necessary to permit a precise correction for temperature effect. Such a measurement can be used to extend useful machine operating time as the long time constant integrates (averages) over temperature variations and may produce a temperature in the test with less variation than laboratory environment. Availability of a record of laboratory environment is necessary to assess the conditions prior to attempting measurement.

\section{VIBRATION}

Vibration is an important factor in measurement. The effects of vibration are most noticeable in light beam galvanometers (nanovolt amplifiers), mercury columns, mass balances, and dimensional measuring equipment. The discontinuance of the use of aperiodic galvanometers has significantly reduced the effects in dc laboratories as nanovolt amplifiers show a much lower response and electronic detectors show almost no response. Also, for 
electronic balances, the effects of vibration are significantly reduced compared to single- or double-pan balances; however, the sensitivity is also about $10 x$ less for the electronic balances. Mass balances are the most affected by vibration, but it is recommended that a low vibration level be maintained in the entire standards laboratory.

Achieving a low vibration level is a matter of proper building design and site selection. An isolated floor pad is of great benefit in achieving low vibration levels. Recommended vibration control goal is 0.25 mmeter ( 10 $\mu$ inch) maximum displacenent amplitude from $0.1 \mathrm{~Hz}$ to $30 \mathrm{~Hz}$ and $0.001 \mathrm{~g}$ maximum from $30 \mathrm{~Hz}$ to $200 \mathrm{~Hz}$. The equipment itself is often the best indicator of a vibration problem. Vibration may be reduced by isolation through specialized mounts or alr-bag supports. Use of an isolated massive block can also be of aid in reducing vibration. Air bag and isolated massive block systems make maintaining a level condition difficult as mass positions are changed.

In design and selection of a new facility, it is recommended that a signiflcant design effort be expended in advance of construction towards a minimum vibration. Isolation techniques are then used to minimize the resulting vibration as needed.

\section{E. RELATIVE LABORATORY AIR PRESSURE}

Laboratory air pressure should be maintained at a positive 0.05 to 0.1 inches of water. The purpose is to provide an outflow through leakage channels so that pollutants, particularly particulates, and cold or hot air will not be drawn into the laboratory through leakage channels and on the necessary short time open-door conditions.

\section{F. HUMIDITY}

A relative humidity of $408 \pm 58$ is recommended for all general laboratories, except for mass, force, and dimensional. This humidity range permits a relatively-simple environmental control, is sufficient to minimize electrostatic effects, and is not sufficient to create troublesome electrical leakage paths. It is noted, however, that most electrical/ electronic aquipment is unaffected by humidity in the range of 208 to 50 \& and that the range may be broadened for many applications.

For mass, force, and dimensional laboratories operating at high-precision, the recommended relative humidity is $358 \pm 38$. This relative humidity mandates a non-condensing environmental control (see note below) which is highly desirable where corrosion and/or performance deterioration of equipment may result. It is noted that some mechanical balances are specified fox use in a non-condensing environment. A non-condensing environment is more difficult to achieve and considerably more expensive to implement; accordingly it is recommended only for the specified areas. 
NOTE ON NON-CONDENSING ENVIRONMENT. Most air-conditioning systems operate by producing saturated chilled air and then mixing this moisture-laden cold air with heated air. This mode of operation is efficient and yields about 438 humidity in a $20^{\circ} \mathrm{C}$ environment. However, system dysfunction may deposit a significant amount of moisture on measuring instrument surfaces which can result in corrosion and/or deterioration of function (not a problem at $23^{\circ} \mathrm{C}$ ). System efficlency may be retained and humidity lowered by use of a small secondary chlliling system which usually requires an antifreeze solution for operation. The artificially lowered humidity produced in this double system is a non-condensing environment. Because of significant extra cost, such systems are not warranted except where specific need exists. Reference point for wavelength correction and airdensity (buoyancy) correction is about 438 humidity but proven formulae and the ubiquitous computer of today can readily accommodate the lower humidity level.

\section{G. ILLUMINATION}

Illumination in laboratory areas should be approximately 100 lumens/ft 2 with all lights on. Individual ? ight controls are required for areas where radiant energy can affect measurements (low lllumination pattern must be established for each specific measurement) and are recommended for all laboratory areas.

\section{H. PARTICULATES}

Particulates in the laboratory atmosphere must be controlled to a reasonable degree. Control of particulates in the atmosphere reduces contamination of open oil-baths and dimensional measuring surfaces. A higher degree of control is required in mass measurements. However, clean room conditions and specialized clothing are not necessary for standards laboratory operation. Attention to housekeeping is a must; in the most critical areas, a tack-sheet to remove shoe-borne particles can be helpful. Filtration of laboratory air by normal means is sufficient in nearly all cases. It should be noted that the wet-scrubber used to saturate chilled air is also highly efficient in removing particulates. A problem to keep in mind is the slow accumulation of particulates in ductwork which can be released at a later time.

\section{ELECTROMAGNETIC INTERFERENCE (EMI)}

Most precision electrical and electronic equipment is subject to EMI only to a moderate degree. EMI may be insidious particularly because detection at microvolt and lower voltage levels can show bias by partial

rectification of the interfering signals. Care should be taken in site selection and use of shielding; the goal is to achieve less than 100 $\mu v / m e t e r$ field strength and $100 \mu \mathrm{v}$ open-circult voltage from conducted electromagnetic energy. Neither of these specifications is highly restrictive; $100 \mu \mathrm{v} /$ meter is about the sensitivity of a typical am radio. 
Equipment in electronics often has a relatively-high input impedance permitting simple open leads to pick up enough to cause problems; care in lead-dress and shielding is always recommended.

For those disciplines which have a high susceptibility to EMI, shielded rooms with appropriate attenuation are required. Shielded rooms may also be required where radiation of generated signals must be suppressed.

In addition to possible magnetic pickup, ground loops between instruments and circulating cirrents from the several connected instruments must be avoided. 

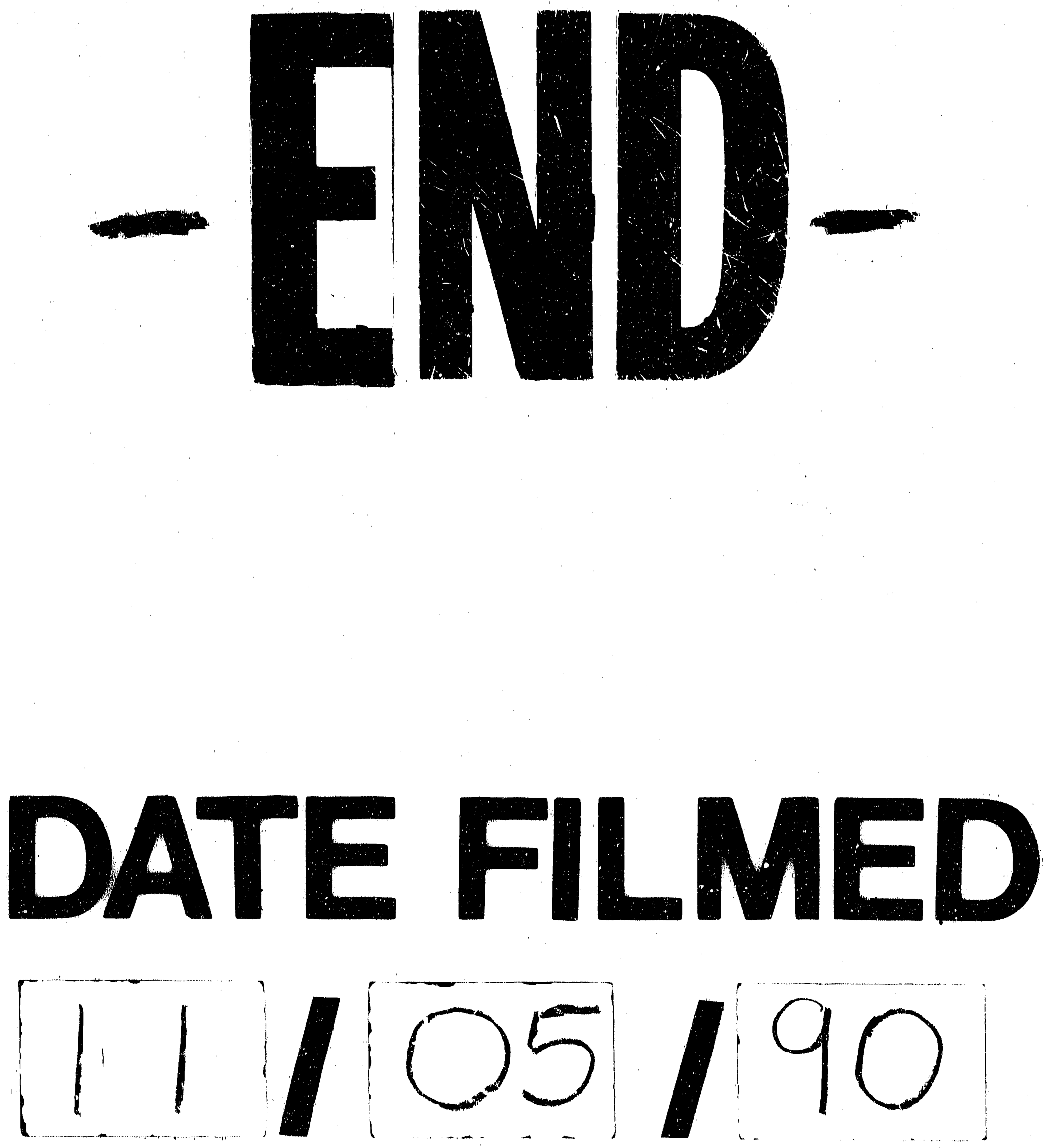

1 
